Research Article

(Araştırma Makalesi)

Sema ÖZÜRETMEN1 10 0000-0002-2071-9296 Hülya ÖZELÇAM ${ }^{1}$ - 0000-0001-6270-0334

${ }^{1}$ Ege Üniversitesi, Ziraat Fakültesi, Zootekni Bölümü, 35100, Bomova-Izmir

Corresponding author: hulya.ozelcam@ege.edu.tr

* ilk Yazarın Yüksek Lisans Tezinden Derlenmiştir.

Anahtar Kelimeler:

Karanfil yağı, saman, sindirilebilirlik, metabolik enerji.

Keywords:

Clove oil, straw, digestibility, metabolizable energy.
J. Anim. Prod., 2019, 60 (1): 9-13

DOI: $10.29185 /$ hayuretim. 485134

\section{Buğday Samanının Karanfil Eterik Yağı ile Muamelesinin in vitro Kuru Madde Sindirilebilirliği ve Metabolik Enerji Değerine Etkisi*}

Effect of Clove Oil Treatment on in vitro Dry Matter Digestibility and Metabolizable Energy Value of Wheat Straw

Alınış (Received): 19.11.2018 Kabul tarihi (Accepted): 09.04.2019

\section{öz}

Amaç: Bu çalışmada, karanfil eterik yağının buğday samanının in vitro kuru madde sindirimi (KMS) ve metabolik enerji (ME) değerlerine etkisinin belirlenmesi amaçlanmıştır.

Materyal ve Metot: Araştırmada, karanfil yağı (\%66.6 eugenol), farklı doz (0, 50, 100 200 ppm) ve saatlerde $(1,3,5,7,9,12)$ buğday samanı ile muamele edilmiştir. Çalışmada, öncelikle in vitro Selülaz yöntemi uygulanmıștır. Yöntemin uygulanmasında Trichoderma viride' den (Onozuka R-10, 1 U/mg aktivite) elde edilen Selülaz enzimi ile Pepsin (2000 FIP-U/g) kullanılmıştır. Daha sonra elde edilen değerlerden, yemin KMS değeri ile enzimde çözünebilen organik madde (ELOS) miktarı bulunmuş ve in vitro ME değerleri hesaplanmıştır.

Bulgular: Karanfil eterik yağı artan doza bağlı olarak, buğday samanının KMS, ELOS ve ME değerlerini artırmıştır $(P<0.01)$. Buna göre, karanfil yağı muamelesi, samanın KMS, ELOS ve ME değerlerini sırasıyla \%37.17 den \%53.92 ye, \%22.31 den \%39.45 e ve $7.53 \mathrm{MJ} / \mathrm{kg}$ dan $8.13 \mathrm{MJ} / \mathrm{kg}$ a yükseltmiştir $(\mathrm{P}<0.01)$. Bu parametrelere ait en yüksek değerler, 200 ppm doz ve 5. saatte elde edilmiştir $(P<0.01, P<0.05)$.

Sonuç: Sonuç olarak, buğday samanına karanfil yağı muamelesi, yemin in vitro sindirimini ve enerji değerini arttırmada önemli potansiyel etkiye sahiptir. Ancak çalışma sonuçları daha detaylı çalışmalarla ve özellikle in vivo çalışmalarla desteklenmelidir.

\section{ABSTRACT}

Objective: This study aimed to determine the effect of clove oil on in vitro dry matter digestibility (DMD) and metabolizable energy (ME) values of wheat straw.

Material and Methods: In the research, clove oil (66.6\% eugenol) was treated with wheat straw at different doses $(0,50,100,200 \mathrm{ppm})$ and hours $(1,3,5,7,9,12)$. Firstly, in vitro cellulase method was applied in the study. In the application of the method, pepsin (2000 FIP-U/g) and also the cellulase enzyme obtained from Trichoderma viride (Onozuka R-10, $1 \mathrm{U} / \mathrm{mg}$ activity) were used. Then from obtained values, the DMD value of the feed and the amount of organic matter soluble in the enzyme (ELOS) were found and the in vitro ME values were calculated.

Results: Clove etheric oil depending on the increasing dose was increased DMD, ELOS and ME values of wheat straw $(P<0.01)$. Accordingly, clove oil treatment, increased the DMD, ELOS and ME values of the straw from $37.17 \%$ to $53.92 \%$, from $22.31 \%$ to $39.45 \%$ and from $7.53 \mathrm{MJ} / \mathrm{kg}$ to $8.13 \mathrm{MJ} / \mathrm{kg}$, respectively $(P<0.01)$. The highest values for these parameters were obtained at $200 \mathrm{ppm}$ dose and 5 hours $(\mathrm{P}<0.01, \mathrm{P}<0.05)$

Conclusion: As a result, clove oil treatment in wheat straw has an important potential effect in increasing the in vitro digestion and energy value of feed. However, the results of the study should be supported by more detailed studies, especially in vivo studies. 


\section{Giriş}

Son yıllarda, eterik yağlar ya da aktif bileşenlerinin in vitro rumen fermentasyonu ve yemin sindirilebilirliği üzerine etkilerini konu alan çalışma sayısı artış göstermiştir (Isman, 2000, Castillejos ve ark., 2007, Yang ve ark., 2010, Benchaar ve ark., 2006, Demirtaş ve ark., 2011). Çalışmalarda, genelde eterik yağların selülotik bakterileri artırarak selüloz sindirimini iyileştirmesi veya proteolitik bakterileri azaltarak protein deaminasyonunu engellemesi, dolayısıyla bypass protein oranını arttırmasına ilişkin etkileri araştırılmıştır (Burt, 2004, Hart ve ark., 2008, Sallam ve ark., 2009). Araştırma sonuçları oldukça değişkenlik gösterip, eterik yağların bazen rumendeki mikrobiyal aktiviteyi uyardığı, fakat genelde olumsuz yönde etkileyerek yemin sindirimi ile metabolik enerji (ME) değerini düşürdüğü bildirilmiştir (Canbolat ve ark., 2010 ve 2011). Konu ile ilgili çalışmaların çoğu, in vitro koşullarda eterik yağların rumen sıvısına ya da yoğun yeme ilavesi şeklinde yürütülmüş, ancak herhangi bir eterik yağın doğrudan kaba yeme ilavesiyle yem değerini etkileyip etkilemediği incelenmemiştir. Nitekim yoğun yeme eterik yağ ilavesinin; tüm sindirim sistemindeki patojen mikroorganizmaları öldürdüğü, yemin lezzetini ve tüketilebilirliğini arttırdığı, enzimlerin etkinliğini arttırarak yemin sindirilebilirliğini yükselttiği ve böylece yemden yararlanmayı iyileştirerek daha fazla ağırlık kazancı sağladığı, amonyağı bağlayarak daha sağlıklı bir çevre oluşturduğu da bildirilmiştir (Kutlu ve Görgülü, 2001, Calsamiglia ve ark., 2007, Tekeli ve ark., 2007, Adıyaman ve Ayhan, 2010).

Diğer yandan eterik yağlar içerisinde, sindirimi uyarıcı ve güçlü bir antimikrobiyal özelliğe sahip olan karanfil eterik yağı (Calsamiglia ve ark., 2007) ile yapılan bir çalışmada, 300 ppm lik dozun yemin in vitro kuru madde sindirimini (KMS) (\%10) ve ME değerini (\%11) arttırdığı bildirilmiştir (Rofiq ve ark., 2012a). Ayrıca karanfil yağının bazı bakterilerin gelişimi üzerine etkilerinin araştırıldığı çalışmalarda, yağın etkinliğinin görülebilmesi için 6 saatlik bir bekleme süresinin gerektiği (Bergvist, 2007) ya da etkinin yağın muamelesinden hemen sonra başlayıp 5 . saate kadar devam ettiği (Machado ve ark., 2011) saptanmıştır. Bununla birlikte karanfil yağının doğrudan kaba yemle muamelesinde, in vitro sonuçlara benzer etkilerin elde edilip edilemeyeceği ve farklı zaman periyodlarındaki muamelenin sonuçları etkileyip etkilemeyeceği de bilinmemektedir. Bu durum, karanfil yağının özelliklerinden dolayı, yemin sindiriminde ve dolayısıyla enerji değerinde bir artış beklentisini oluşturmuştur. Bu beklentiden hareketle çalışmada, buğday samanının farklı doz (50, 100, 200 ppm) ve zaman periyodlarında (1, 3, 5, 7, 9, 12 saat) karanfil yağı ile muamelesinin, in vitro KMS ile ME değerine etkisinin araştırılması amaçlanmıştır.

\section{MATERYAL ve METOT}

\section{Materyal}

Çalışmada yem materyali olarak, ticari bir işletmeden temin edilen buğday (Triticum aestivum L.) samanı kullanılmış, katkı olarak kullanılan karanfil eterik yağı (Syzgium aromaticum, \%66.6 Eugenol içerikli) ise, piyasadaki ticari bir işletmeden (Mecit Efendi) temin edilmiştir.

\section{Metot}

Polietilen torbalara 100'er g tartılan yem örneklerinden, biri kontrol (karanfil yağı ilavesiz) olmak üzere toplam 4 muamele grubu oluşturulmuştur. Samanlar farklı doz $(0,50,100,200$ ppm) ve zaman periyodlarında $(1,3,5,7,9,12$ saat) karanfil yağı ile muamele edilmiş ve deneme iki farklı zamanda tekrarlanmıştır. Karanfil yağının samanlara ilavesinin hemen ardından torbalar sıkıca kapatılıp, alt üst yapılarak yağın samana iyice nüfus etmesi sağlanmış ve inkübasyon periyodu süresince torbalar kuru ve karanlık bir yerde muhafaza edilmiştir. İnkübasyon süreleri sonunda, torbalar açılarak, samanların önce besin madde içerikleri (kuru madde: KM, ham kül: HK, ham yağ: HY, ham selüloz: HS) belirlenmiş (AOAC, 1990), daha sonra in vitro Selülaz yöntemi ile KMS değerleri ve enzimde çözünebilen organik madde (ELOS) miktarları saptanmıştır. Araştırmada selülaz yöntemi olarak Tilley ve Terry (1963)'nin geliştirdiği enzimatik yöntemin modifikasyonundan yararlanılmıştır (De Boever ve ark, 1986). Yöntemin uygulanmasında Trichoderma viride' den (Onozuka R10, $1 \mathrm{U} / \mathrm{mg}$ aktivite) elde edilen Selülaz enzimi ile Pepsin (2000 FIP-U/g) enzimi kullanılmıştır. Çalışmada tüm analitik işlemler eş zamanlı yürütülmüştür. Ayrıca aşağıdaki eşitlikler kullanılarak samanların KMS değerleri ile bazı besin maddeleri ve ELOS değerlerinden yararlanılarak in vitro ME değerleri de hesaplanmıştır (GfE, 1998).

KMS, \% $=\left(\left(A_{n}-\left(A_{k}-A_{0}\right)\right) / A_{n}\right) \times 100$

$E L O S, \%=K M-H K-G^{*} \quad{ }^{*} G, \%=\left(\left(A_{k}-A_{y}\right) / A_{n}\right) \times 100$ $M E(M J / k g ~ K M)=-1,04+(0,00001611 \times E L O S \times E L O S)+(0,3724 \times H Y)-$ $(0,0003674 \times E L O S \times H Y)-(0,0004919 \times H Y \times H S)+(0,01548 \times H S)$

Eşitliklerdeki; $A_{\circ}$ : cam krozenin darası (g); $A_{n}$ : numune ağırlığı (g); $A_{k}$ : $105^{\circ} C^{\prime}$ deki kuru ağır. (g); $A_{y}$ : $550^{\circ} \mathrm{C}^{\prime}$ deki yanmış ağır. (g) ; KM: yemin kuru madde içeriği (\%); HK: yemin ham kül içeriği (\%); HY: yemin 
ham yağ içeriği (\%); HS: yemin ham selüloz içeriği (\%)'ni ifade eder.

Bulguların istatistiki değerlendirmesinde SPSS programından yararlanılmış, ortalamalar arası farklar Duncan testi $(\mathrm{P}<0.01, \mathrm{P}<0.05)$ ile karşılaştırılmıştır (SPSS, 2009).

\section{BULGULAR ve TARTIŞMA}

Çalışmanın ilk aşamasında, karanfil eterik yağının farklı doz ve zaman periyodlarında buğday samanının in vitro KMS değerlerine etkisi araştırılmıştır. Buna göre, doz artışına bağlı olarak samanın KMS değerleri önemli düzeyde artmıştır ( $P<0.01$, Çizelge 1). Kontrole (\%37.17) kıyasla, KMS üzerine karanfil yağının etkinliği bakımından en yüksek artış, \%53.92 ile 200 ppm doz ve 5 . saatte bulunmuştur $(P<0.01, P<0.05)$. Bu bulgu, Bergvist (2007) ile Newbold ve ark. (2004) nın bazı eterik yağların etkinliğinin görülebilmesi için yaklaşık 6 saat beklenmesi gerektiği bildirişleriyle uyumludur. Çalışmanın KMS değerleri, Yılmaz (2009) ile Sallam ve ark. (2009)' nın bildirişleriyle de uyumludur. Nitekim Yılmaz (2009), rumen sıvısına 150 ppm çörekotu yağı ilavesinin, buğday samanının KMS'ni \%88'den \%91'e yükselttiğini bildirmiştir. Aynı şekilde Şahan ve ark. (2009), rumen sıvısına farklı dozlarda ilave edilen nane ve defne yağı ilavesinin buğday samanının KMS'ni arttırdığını, kontrole (\%42.24) kıyasla, en yüksek etkinin nane için 100 ppm (\%43.55) ve defne için 50 ppm (\%45.64) dozlarda olduğunu saptamıştır. Rofiq ve ark. (2012a), rumen sıvısına farklı dozlarda karanfil yağı ilavesinin TMR'ın (\%60 yoğun+\%40 yonca otu) KMS'ni kontrole (\%76.19) kıyasla, 200 ve 300 ppm dozlarda (sırasıyla \%78.83 ve 81.41) arttırdığını, hatta hücre çeperi sindiriminin \%37'den \%51'e yükseldiğini ortaya koymuştur. Diğer yandan KMS için elde edilen bulgular, farklı ekstraktların KMS'ni \%6-7 oranında azalttığı (Patra ve ark., 2006), 200 ppm karanfil yağının rumen sıvısına ilavesinin KMS'ni etkilemediği (Benchaar ve ark., 2008), 250 ppm adaçayı ve biberiye ekstraktı ilavesinin arpa samanının KMS'ni değiştirmediği
(Demirtaş ve ark., 2011) bildirişleriyle uyum sağlamamıştır. Bu durum, kullanılan eterik yağın çeşidine, etken madde miktarına, doza, uygulama şekline ve yöntem farklılıklarına dayandırılabilir. Bununla birlikte karanfil yağının selülotik bakteri aktivasyonunu sağlamada etkili olduğu yönünde çalışma sayısı da oldukça azdır (Rofiq ve ark, 2012a ve b). Çalışmamızdaki karanfil yağının samanın KMS üzerinde yaptığı olumlu etkinin, hücre zarı geçirgenliğini etkileme ve hücre içindeki önemli işlevlerin (elektron transferi, fosforilasyon aşamaları, enzime bağlı reaksiyonlar gibi) bozulması, dolayısıyla metabolizmayı yıkıma uğratma yoluyla olduğu düşünülmektedir (Brenes ve Roura, 2010; Chamdit ve Siripermpool, 2012; Ünlü ve ark, 2013). Ayrıca karanfil yağının brokoli yaprak yüzeyinin geçirgenliğini arttırdığını ve bunun da yapraktaki elektrolit yıkımı ile gerçekleştiğini bildiren bir çalışma (Stocklosa ve ark, 2012) da sonuçlarımızı desteklemektedir. Dolayısıyla samanın in vitro sindiriminin artışına ilişkin bulgularımıza dayanarak, karanfil yağının selülotik aktiviteyi olumlu yönde etkilediği söylenebilir.

Çalışmanın ikinci aşamasında, karanfil yağının farklı doz ve zaman periyodlarında, samanın in vitro ELOS ve ME değerlerine etkisi araştırılmıştır. Buna göre, karanfil yağı doz artışına bağlı olarak ELOS ve ME değerlerini arttırmıştır ( $P<0.01$, Çizelge 2 ve 3 ). Bilindiği üzere, yemin enzimde çözünebilir madde miktarı ile sindirilebilirlik ve enerji değeri arasında oldukça yüksek korelasyonlar (sırasıyla $r=0.86$ ve $r=0.91$ ) olup, yemin ELOS değeri arttıkça enerji değeri de artmaktadır (Şayan ve ark, 2003). Çizelge 2'de, kontrole (\%22.31) kıyasla, ELOS değerine karanfil yağının etkinliği bakımından en yüksek artış (\%39.45), 200 ppm doz ve 5 . saatte bulunmuştur $(\mathrm{P}<0.01, \mathrm{P}<0.05)$. Kontrol grubuna ait ELOS değeri, Şayan ve ark. (2003)'nın bildirdiği \%23.0-39.5 değerleriyle uyum sağlamış, ancak eterik yağların yemin ELOS değerine etkilerinin incelendiği bir literatüre rastlanılmamıştır.

Çizelge 1. Karanfil yağının samanın in vitro KMS değerine etkisi

Table 1. The effect of clove oil on the in vitro DMD value of straw

\begin{tabular}{|c|c|c|c|c|c|c|c|}
\hline \multirow[b]{2}{*}{$\begin{array}{l}\text { Doz, } \\
\text { ppm }\end{array}$} & \multicolumn{6}{|c|}{ Muamele süresi (Saat) } & \multirow[b]{2}{*}{ P** değeri } \\
\hline & 1 & 3 & 5 & 7 & 9 & 12 & \\
\hline 0 & $37.17 \pm 0.61^{c}$ & $37.17 \pm 0.31^{c}$ & $37.17 \pm 0.61^{c}$ & $37.17 \pm 0.61^{c}$ & $37.17 \pm 0.61^{b}$ & $37.17 \pm 0.61^{c}$ & \\
\hline 50 & $45.60 \pm 0.47^{b}$ & $43.76 \pm 1.85^{b}$ & $47.12 \pm 0.70^{b}$ & $43.55 \pm 0.85^{b}$ & $43.58 \pm 1.00^{b}$ & $45.19 \pm 0.61^{b}$ & 0.06 \\
\hline 100 & $48.72 \pm 0.25^{\mathrm{ab}}$ & $45.76 \pm 1.82^{\mathrm{ab}}$ & $49.37 \pm 0.44^{b}$ & $46.70 \pm 0.82^{b}$ & $47.79 \pm 0.89^{a}$ & $47.64 \pm 0.36^{b}$ & 0.17 \\
\hline 200 & $51.13 \pm 0.36^{\mathrm{aAB}}$ & $50.10 \pm 1.29^{\mathrm{aAB}}$ & $53.92 \pm 0.84^{\mathrm{aA}}$ & $52.03 \pm 0.83^{\mathrm{aAB}}$ & $49.50 \pm 0.96^{\mathrm{aB}}$ & $51.42 \pm 1.33^{\mathrm{aAB}}$ & 0.05 \\
\hline P* değeri & 0.00 & 0.00 & 0.00 & 0.00 & 0.00 & 0.00 & \\
\hline
\end{tabular}

*Aynı sütunda farklı küçük harf taşıyan ortalamalar arası farklar önemlidir $(\mathrm{P}<0.01)$.

** Aynı satırda farklı büyük harf taşıyan ortalamalar arası farklar önemlidir $(P<0.05)$. 
Özüretmen ve Özelçam

Çizelge 2 Karanfil yağının samanın in vitro ELOS değerine etkisi Table 2. The effect of clove oil on in vitro ELOS value of straw

\begin{tabular}{|c|c|c|c|c|c|c|c|}
\hline \multirow[b]{2}{*}{$\begin{array}{l}\text { Doz, } \\
\text { ppm }\end{array}$} & \multicolumn{6}{|c|}{ Muamele süresi (Saat) } & \multirow[b]{2}{*}{$\begin{array}{c}\mathbf{P} * * \\
\text { değer }\end{array}$} \\
\hline & 1 & 3 & 5 & 7 & 9 & 12 & \\
\hline 0 & $22.31 \pm 0.57^{c}$ & $22.31 \pm 0.57^{b}$ & $22.31 \pm 0.57^{c}$ & $22.31 \pm 0.57^{c}$ & $22.31 \pm 0.57^{c}$ & $22.31 \pm 0.57^{d}$ & \\
\hline 50 & $33.06 \pm 0.51^{\mathrm{bA}}$ & $26.46 \pm 0.74^{\mathrm{bB}}$ & $33.61 \pm 0.58^{\mathrm{bA}}$ & $28.07 \pm 1.33^{\mathrm{bB}}$ & $29.18 \pm 1.40^{\mathrm{bB}}$ & $28.97 \pm 0.90^{\mathrm{CB}}$ & 0.00 \\
\hline 100 & $34.90 \pm 0.66^{\mathrm{abA}}$ & $25.78 \pm 1.07^{\mathrm{bB}}$ & $35.33 \pm 0.38^{\mathrm{bA}}$ & $32.19 \pm 1.42^{\mathrm{bA}}$ & $34.69 \pm 0.67^{\mathrm{aA}}$ & $32.77 \pm 0.69^{\mathrm{bA}}$ & 0.00 \\
\hline 200 & $36.09 \pm 0.42^{\mathrm{aB}}$ & $35.36 \pm 1.32^{\mathrm{aB}}$ & $39.45 \pm 0.72^{\mathrm{aA}}$ & $38.43 \pm 0.86^{\mathrm{aAB}}$ & $36.05 \pm 1.04^{\mathrm{aAB}}$ & $37.69 \pm 0.70^{\mathrm{aAB}}$ & 0.00 \\
\hline $\mathbf{P} *$ değeri & 0.00 & 0.00 & 0.00 & 0.00 & 0.00 & 0.00 & \\
\hline
\end{tabular}

* Aynı sütunda farklı küçük harf taşıyan ortalamalar arası farklar önemlidir $(\mathrm{P}<0.01)$.

** Aynı satırda farklı büyük harf taşıyan ortalamalar arası farklar önemlidir $(P<0.05)$.

Çizelge 3 Karanfil yağının samanın in vitro ME değerine etkisi

Table 3. The effect of clove oil on in vitro ME value of straw

\begin{tabular}{|c|c|c|c|c|c|c|c|}
\hline \multirow[b]{2}{*}{$\begin{array}{l}\text { Doz, } \\
\text { ppm }\end{array}$} & \multicolumn{6}{|c|}{ Muamele süresi (Saat) } & \multirow[b]{2}{*}{$\begin{array}{c}\mathbf{P} * * \\
\text { değeri }\end{array}$} \\
\hline & 1 & 3 & 5 & 7 & 9 & 12 & \\
\hline 0 & $7.53 \pm 0.03^{c}$ & $7.53 \pm 0.03^{c}$ & $7.53 \pm 0.03^{c}$ & $7.53 \pm 0.03^{c}$ & $7.53 \pm 0.03^{b}$ & $7.53 \pm 0.03^{c}$ & \\
\hline 50 & $7.72 \pm 0.03^{\mathrm{bAB}}$ & $7.69 \pm 0.07^{\mathrm{bABC}}$ & $7.80 \pm 0.03^{\mathrm{bA}}$ & $7.67 \pm 0.06^{\mathrm{bcABC}}$ & $7.58 \pm 0.04^{\mathrm{bBC}}$ & $7.65 \pm 0.04^{\text {bc } A B C}$ & 0.00 \\
\hline 100 & $7.80 \pm 0.05^{\mathrm{abA}}$ & $7.75 \pm 0.08^{\mathrm{abA}}$ & $7.88 \pm 0.02^{\mathrm{bA}}$ & $7.74 \pm 0.05^{\mathrm{bA}}$ & $7.80 \pm 0.04^{\mathrm{aA}}$ & $7.76 \pm 0.03^{\mathrm{bA}}$ & 0.00 \\
\hline 200 & $7.93 \pm 0.02^{\mathrm{aAB}}$ & $7.92 \pm 0.09^{\mathrm{aAB}}$ & $8.13 \pm 0.05^{\mathrm{aA}}$ & $8.00 \pm 0.06^{\mathrm{aAB}}$ & $7.86 \pm 0.06^{\mathrm{aB}}$ & $7.84 \pm 0.05^{\mathrm{aAB}}$ & 0.00 \\
\hline P* değeri & 0.00 & 0.00 & 0.00 & 0.00 & 0.00 & 0.00 & \\
\hline
\end{tabular}

* Aynı sütunda farklı küçük harf taşıyan ortalamalar arası farklar önemlidir $(\mathrm{P}<0.01)$.

** Aynı satırda farklı büyük harf taşıyan ortalamalar arası farklar önemlidir $(P<0.05)$.

ELOS değerine karanfil yağı etkinliği bakımından en yüksek değerler, in vitro sindirilebilirlikte olduğu gibi, 5. saatte gerçekleşmiştir $(P<0.05)$. Nitekim Rofiq ve ark. (2012b), karanfil yağının doğrudan TMR'a ilavesinde, yemin çözünemeyen fraksiyonlarına etkisinin olmadığını, fakat "karanfil+tarçın yağı" kombinasyonunun, fraksiyonların çözünebilirliğini artırdığını bildirmişlerdir.

Diğer yandan Çizelge 3'de, karanfil yağı ilavesinin artan dozlarıyla birlikte ME değerinin arttığı yönündeki bulgular, çoğu literatürle uyumlu değildir (Canbolat ve ark. 2010; Canbolat ve ark. 2011; Salamatazar ve ark. 2011; Kamalak ve ark. 2011; Canbolat, 2012). Çalışmada kontrol grubuna ait ME değeri $(7.53 \mathrm{MJ} / \mathrm{kg})$, Canbolat (2012)'ın bildirdiği ortalamalardan (10.3-10.8 $\mathrm{MJ} / \mathrm{kg}$ ) oldukça düşük bulunmuştur. Bu durum, söz konusu çalışmalarda kullanılan yemlerin farklılığına dayandırılabilir. Bununla birlikte, ME değeri bakımından en yüksek artışlar (+ \%8), yine 200 ppm doz ve 5 . saatte saptanmıştır $(P<0.01, P<0.05)$. Ayrıca

\section{KAYNAKLAR}

AOAC 1990. Official method of analysis, 15 th Ed, Association of Official Analytical Chemists, Inc., Virginia, USA, 770-771.

Adıyaman, E. ve Ayhan, V. 2010. Etlik piliçlerin beslenmesinde aromatik bitkilerin kullanımı, 51 (1), 57-63.

Benchaar C, Calsamiglia S, Chaves AV, Fraser GR, Colombatto D, McAllister TA, Beauchemin KA. 2008. A review of plant derived essential oils in ruminant nutrition and production. Anim Feed Sci Technol, 145, 209-228.
50 ppm doz ve 5. saatte elde edilen ME değerinde de, + \%4 oranında bir artış kaydedilmiştir. Bu bulgu, Canbolat ve ark. (2011)'nın, ruminal performansı olumsuz etkilememek için, eterik yağların düşük dozda kullanılması gerektiğine yönelik bildirişi destekler niteliktedir.

\section{SONUÇ}

Buğday samanına artan dozlarda karanfil yağı ilavesi, yemin in vitro KMS, ELOS ve ME değerlerini önemli düzeyde arttırmıştır. Araştırmada, samanın in vitro sindirimi ve enerji değeri üzerine en etkili doz ve zaman periyodunun, 200 ppm ve 5 . saat olduğu ortaya konmuştur. Buna göre, karanfil yağı ilavesi, samanın sindirimini ve enerji değerini arttırmada potansiyel bir etkiye sahiptir. Ancak eterik yağlarla yapılan çoğu çalışma gibi, bu çalışma da in vitro koşullarda geçerli olup, konunun daha iyi irdelenmesi amaciyla daha fazla ve özellikle de in vivo çalışmalara ihtiyaç vardır.

Benchaar C, Duynisveld JL, Charmley E. 2006. Effects of monensin and increasing dose levels of a mixture of essential oil compounds on intake, digestion and growth performance of beef cattle. Can J Anim Sci, 86, 91-96.

Bergvist TP. 2007. Antimicrobial activity of four volatile essential oils. Master thesis in Pharmacy, Göteburg University, 10p.

Brenes A, Roura, E. 2010. Essensial oils in poultry nutrition: Main effects and modes of action. Anim Feed Sci Technol, 158, 1-14 
Burt S. 2004. Essential oils: their antibacterial properties an potential application in foods. A review: Int. J Food Microbiol. 94, 223-253.

Calsamiglia S, Busquet M, Cardozo PW, Castillejos L, Ferret A. 2007. Invited review: essential oils as modifiers of rumen microbial fermentation. J Dairy Sci. 90, 2580-2595.

Chamdit S, Siripermpool P. 2012. Antimicrobial effect of clove and lemongrass oils againts planktonic cells and biofilms of Staphylococcus aureus. Mahidol Uni, J Pharmaceutical Sci, 39 (2), 28-36.

Canbolat Ö. 2012. Comparison of in vitro gas production, organic matter digestibility, relative feed value and metabolizable energy contents of some cereal forages. J Faculty Vet Med, University of Kafkas, 18 (4), 571-577.

Canbolat Ö, Kalkan H, Karaman Ş, Filya İ. 2011. Esansiyel yağların sindirim, rumen fermantasyonu ve mikrobival protein üretimi üzerine etkileri, Kafkas Üniv Vet Fak Derg, 17 (4), 557-565.

Canbolat Ö, Karaman Ş, Filya İ. 2010. Farklı kekik yağı dozlarının mısır silajının sindirimi ve rumen fermantasyonu üzerine etkileri. Kafkas Univ Vet Fak Derg, 16 (6), 933-939.

Castillejos L, Calsamiglia S, Ferret A, Losa R. 2007. Effects of dose and adaptation time of a specific blend of essential oil compounds on rumen fermentation. Anim Feed Sci Technol, 132: 186-201.

Demirtaş A, Öztürk H, Pişkin İ, Demirkiran D, Salgirli Y. 2011. Biberiye ve adaçayı ekstraktlarının ruminal fermantasyon üzerine etkilerinin rumen simülasyon tekniği (RUSITEC) ile araştırılması. İstanbul Üniv Vet Fak Derg, 37 (2), 127-134.

De Boever, J.L., Cottyn, B.G., Buysse, F.X., Waiman, F.W., Vanacker, J.M. 1986. The use of on enyzmatic techniqueto predict digestibility, metabolizable energy of compound feedstuffs for ruminants, Anim Feed Sci Technol, 14, 203-214.

GfE 1998. Ausschuss für Bedarfsnormen der Gesellschaft für Ernahrungsphysiologie. Proc Soc Nutr Physiol, 7, 141-149.

Hart, KJ, Y'a nez-Ruiz, DR., Duval, SM., McEwan, NR., Newbold, CJ. 2008. Plant extracts to manipulate rumen fermentation. Anim Feed Sci Technol, 147, 8-35.

Isman, MB. 2000. Plant essential oils for pest and disease management. Crop Prod, 19: 603-608.

Kamalak, A, Canbolat, Ö, Özkan, O, Atalay, AI. 2011. Effect of thymol on in vitro gas production, digestibility and metabolisable energy content of alfalfa hay. Kafkas Univ Vet Fak Derg, 17 (2), 211-216.

Kutlu, H.R. ve Görgülü, M., 2001. Kanatlı yemlerinde yem katkı maddesi olarak kullanılan antibiyotik-büyütme faktörü için alternatifler. Yem Magazin Derg, 27, 45-62.

Machado, M, Dinis, AM, Salgueiro, L, Custódio, José BA, Cavaleiro, C, Sousa, MC. 2011. Anti-Giardia activity of Syzygium aromaticum essential oil and eugenol: Effects on growth, viability, adherence and ultrastructure. Experimental Parasitology, 127, 732-739

Newbold, CJ., McIntosh, FM., Williams, P, Losa, R, Wallace, RJ. 2004. Effects of a specific blend of essential oil compounds on rumen fermentation. Anim Feed Sci Technol, 114, 105-112.

Patra, A.K., Kamra, D.N., Agarwal, N. 2006. Effect of plant extracts on in vitro methanogenesis, enzyme activities and fermentation of feed in rumen liquor of buffalo. Anim Feed Sci Technol, 128 (3-4), 276 291.
Rofiq, MN., Görgülü, M., Boğa, M. 2012a. Karanfil uçucu yağının (Clove oil) ruminantlarda in vitro gerçek KM ve NDF sindirilebilirliği ve yemin enerji içeriğine etkileri. 8. Ulusal Zootekni Öğrenci Kong, 127-129s.

Rofiq, M.N., Martono, S., Görgülü, M., Boğa, M. 2012b. Combination effect of clove and cinnamon oil on in vitro rumen gas and methane production, Proceeding of the 2nd International Seminar on Animal Industry, 717p.

Sallam, S.M.A., Bueno, I.C.S., Brigide, P., Godoy, P.B., Vitti, D.M.S.S., Abdalla, A.L. 2009. Investigation of potential new opportunities for plant extract on rumen microbial fermentation in vitro. Options Méditerrannées, 85, 255-260.

Salamat Azar., M. R. Salamat Doust-Nobar, Y.Asadi, M Kiani Nahand, S Najafyar,B. Khodaparast, H. Aminipour. 2011. Effect of thyme water extract $(0,1 \mathrm{ml} / 30 \mathrm{ml}$ buffered rumen fluid) on short chain fatty acid, net energy for lactation, metobolizable energy and organic matter digestibility of soybean meal using in vitro gas production technique, J American Sci, 7, 127-130.

SPSS Inc. Released 2009, PASW Statistics for Windows, version 18.0. Chicago: SPSS Inc.

Stokłosa A., Matraszek R., Isman M.B. and Upadhyaya M.K. 2012. Phytotoxic activity of clove oil, its constituents, and its modification by light intensity in broccoli and common lambsquarters (Chenopodium album), Weed Science, 60:607-611.

Şahan, Z., Boğa, M., Çelik, L., Görgülü, M. 2009. Nane (Mentha longifolia), kişniş (Coriandrum sativum), defne (Laurus nobilis), biberiye (Rosmarinus officinalis) uçucu yağlarının buğday samanı, SFK ve arpanın in vitro gercek sindirilebilirliklerine etkileri, 6. Ulusal Zootekni Kong., Erzurum, 24-26 Haziran, 141-145.

Şayan, Y., Özkul, H., Alçiçek, A., Akbaş, Y., Coşkuntuna, L., Önenç, S., Polat, C., Çapçı, T., Kılıç, A., Özkan, K. 2003. Bazı kaba yemlerin yem değerlerinin farklı analiz teknikleri ile belirlenmesi. TÜBİTAK (VHAG-1491) Sonuç Raporu, İzmir, 60s.

Tekeli, A., Celik, L., Kutlu, H.R. ve Görgülü, M. 2007. Effect of Syzygium aromaticum and Zingeber officinale essential oils on performance and some carcass, blood and intestinal parameters of broilers, $57^{\text {th }}$ Annual Meeting of The Europan Association for Animal Production (EAAP), 17-20 September 2006, Antalya, TURKEY.

Tilley, J.M.A., Terry, R.A. 1963. A two stage technique for the in vitro digestion of forage crops. J The British Garssland Society, (18), 104-111.

Ünlü, H.B., Erkek, R., Özdoğan, M., Mert, S. 2013. Buzağ beslemede doğal yem katkı maddelerinin kullanımı, Hayvansal Üretim, 54 (2), 36-42.

Yang, W.Z., Benchaarb, C., Ametajc, B.N., Beauchemin, K.A. 2010. Dose response to eugenol supplementation in growing beef cattle: ruminal fermentation and intestinal digestion. Anim Feed Sci Technol, 158 (1-2), 57-64.

Yılmaz, Y. 2009. Kekik (Origanum vulgare) ve çörekotu (Nigella sativa) yağı ile arpa, soya fasulyesi küspesi ve buğday samanının gercek kuru madde, organik madde ve NDF sindirilebilirliğine etkileri. Yüksek Lisans Tezi, Cukurova Üniv Zootekni ABD., 39s. 